\title{
Teachers' beliefs about using a professional development plan
}

Citation for published version (APA):

Janssen, S., Kreijns, K., Bastiaens, T., Stijnen, S., \& Vermeulen, M. (2013). Teachers' beliefs about using a professional development plan. International Journal of Training and Development, 17(4), 260-278.

https://doi.org/10.1111/ijtd.12016

DOI:

10.1111/ijtd.12016

Document status and date:

Published: 01/12/2013

Document Version:

Peer reviewed version

Document license:

CC BY-SA

Please check the document version of this publication:

- A submitted manuscript is the version of the article upon submission and before peer-review. There can be important differences between the submitted version and the official published version of record. People interested in the research are advised to contact the author for the final version of the publication, or visit the DOI to the publisher's website.

- The final author version and the galley proof are versions of the publication after peer review.

- The final published version features the final layout of the paper including the volume, issue and page numbers.

Link to publication

\section{General rights}

Copyright and moral rights for the publications made accessible in the public portal are retained by the authors and/or other copyright owners and it is a condition of accessing publications that users recognise and abide by the legal requirements associated with these rights.

- Users may download and print one copy of any publication from the public portal for the purpose of private study or research.

- You may not further distribute the material or use it for any profit-making activity or commercial gain

- You may freely distribute the URL identifying the publication in the public portal.

If the publication is distributed under the terms of Article 25fa of the Dutch Copyright Act, indicated by the "Taverne" license above, please follow below link for the End User Agreement:

https://www.ou.nl/taverne-agreement

Take down policy

If you believe that this document breaches copyright please contact us at:

pure-support@ou.nl

providing details and we will investigate your claim.

Downloaded from https://research.ou.nl/ on date: 26 Apr. 2023 


\title{
Teachers' beliefs about using a professional development plan
}

\author{
Sandra Janssen, Karel Kreijns, Theo J. Bastiaens, \\ Sjef Stijnen and Marjan Vermeulen
}

\begin{abstract}
Professional development plans (PDPs) have recently been introduced in Dutch schools to support teachers' professional development. However, teachers' beliefs regarding the use of PDPs have not been systematically researched, whereas research on the use of PDPs indicates that the implementation is not always successful and depends on how use is perceived by users. Some teachers may doubt the usefulness and purpose of a PDP, and this might influence their reactions to its introduction. Using Fishbein and Ajzen's theory of planned behaviour, the current study explored teachers' characteristics (such as age and years of experience in education) and their beliefs about intention to use a PDP. Clusters of teachers with similar characteristics and beliefs were identified to permit the design of interventions specific to each cluster. Semi-structured interviews were conducted to reveal these beliefs and characteristics for a sample of 41 teachers working in schools where using a PDP was mandatory. The results showed that most teachers had a positive attitude towards using a PDP. However, because using a PDP was mandatory, they felt pressured to produce one. Moreover, it was not a priority. This was because of their high workload. The present study contributes to the literature by adding knowledge of teachers' beliefs about the use of PDPs. This knowledge may help the PDP to become a more effective device in promoting teachers' professional development.
\end{abstract}

\footnotetext{
$\square$ Sandra Janssen, Educational consultant/teacher, Fontys University of Applied Sciences, Eindhoven, the Netherlands. Email: sandra.janssen3@gmail.com. Karel Kreijns, Associate professor, Open University, Heerlen, The Netherlands. Email: karel.kreijns@ou.nl. Theo J. Bastiaens, Professor of educational technology, Open University, Heerlen, The Netherlands. Email: theo.bastiaens@ou.nl. Sjef Stijnen, Professor of distance education, Open University, Heerlen, The Netherlands. Email: sjef.stijnen@ou.nl. Marjan Vermeulen, Associate professor, Open University, Heerlen, The Netherlands. Email: marjan.vermeulen@ou.nl
} 


\section{Introduction}

Professional development plans (PDPs) are increasingly used to promote teachers' professional development. A PDP helps teachers to structure their professional development in terms of learning goals and plans of action. Moreover, teachers are expected to be more proactive in their professional development (Imhof \& Picard, 2009; Tigelaar et al., 2006b). A PDP can also form a basis for a critical dialogue between teachers and supervisors (Beausaert et al., 2011b; Fenwick, 2003).

Although the literature emphasizes the value of using a PDP, it also shows mixed evidence regarding its effectiveness (e.g. Austin et al., 2005). Furthermore, views of users about the value of using a PDP varies (e.g. Imhof \& Picard, 2009). The implementation of a PDP in an organization is often a top-down process and that might influence its acceptance by teachers (Fullan, 2001), especially if one considers that the use of PDPs in Dutch schools is rather new. Teachers might have their own beliefs about the usefulness and purpose of PDPs, and these beliefs might determine how teachers act on this introduction (Fishbein \& Ajzen, 2010; Spillane et al., 2002).

\section{Research objectives}

The current study explored teachers' outcome, normative and efficacy beliefs about completing a PDP, and the characteristics of teachers that might influence these beliefs. The characteristics include years of experience and teachers' motives to develop themselves. We aimed to identify clusters of teachers with similar beliefs. With this knowledge, the guidance provided to teachers can be improved and adjusted to clusters of teachers with similar beliefs about completing a PDP.

\section{Research on PDPs}

A portfolio can be used in several professional settings. In work settings, PDPs are used to assess competences or to promote professional development (Beausaert et al., 2011c; Zeichner \& Wray, 2001). In educational settings, portfolios are used by (student) teachers to support them in reflecting on their performance, planning their learning and showing their competences (e.g. Wade \& Yarbrough, 1996; Wolf \& Dietz, 1998). A portfolio includes a collection of evidence of performance and development, and is directed by personal learning goals (Smith \& Tillema, 2001). In our study, we focus on the part of the portfolio that is designated as a PDP, where teachers reflect on their past performance, formulate learning goals to improve their performance and formulate plans of action to achieve their goals (Bullock et al., 2007; Evans et al., 2002). Although the primary purpose of a PDP is to promote professional development, it may have several other purposes at the same time (Imhof \& Picard, 2009), such as promoting dialogue between teachers and supervisors (Beausaert et al., 2011c; Smith \& Tillema, 2001). In schools, the PDP is also instrumental in giving form to the cycle in which teachers get a development and/or performance interview, update the PDP and receive evaluations from their supervisor, colleagues and students. For practical reasons, we refer to PDPs when reporting results of studies on PDPs and portfolios as they are often referred to in the same literature.

\section{Value of using a PDP}

Several studies emphasized the value of a PDP. The questions and activities in a PDP support reflection and promote greater self-awareness and insight. Writing down learning goals provides learners with focus and commitment to their professional development. Teachers can document how they learn and develop themselves (Austin et al., 2005; Imhof \& Picard, 2009; Smith \& Tillema, 2001). Moreover, discussing professional development with a supervisor provides an opportunity to align individual learning goals with school goals and motivates teachers to professionalize themselves (Van Eekelen et al., 2006). Several studies revealed that participants valued using a PDP. They found it useful for planning development (Bullock et al., 2007) and becoming 
aware of performance, and it enhanced their knowledge and skills (Evans et al., 2002; Tigelaar et al., 2006a; Wade \& Yarbrough, 1996).

However, despite these benefits, the process of implementing PDPs is often complex, and results of studies revealed that the effectiveness of the PDP differed, for example, regarding the amount of learning activities. Effects were measured on various aspects of professional development (e.g. Beausaert et al., 2011b; Driessen et al., 2007). These aspects include the amount of learning activities (Austin et al., 2005; Bullock et al., 2007), improved performance and expertise growth (Beausaert et al., 2011a; Tigelaar et al., 2006a), increased awareness (Evans et al., 2002) and reflection (e.g. Mansvelder-Longayroux et al., 2007; Orland-Barak, 2005). Several studies also revealed that users were sceptical about the excessive time it cost and that they doubted the relevance for their own learning needs (Austin et al., 2005; Leggett \& Bunker, 2006).

Research explained these mixed findings and views as follows. When users think that the focus of a PDP is on promotion, instead of development, it can prevent them from reflecting critically on their performance and mentioning opportunities for learning (Imhof \& Picard, 2009; Leggett \& Bunker, 2006). Unclear purpose and guidelines for using a PDP led to frustration and misunderstanding (Austin et al., 2005; Smith \& Tillema, 2003). Additionally, these mixed views can be explained by individual differences. Research by Imhof and Picard (2009) revealed that teachers with a strong proactive attitude regarding professional development found the PDP more useful than teachers with a weak proactive attitude. Wade and Yarbrough (1996) found that some students acknowledged that they learned from the reflection, whereas other students were frustrated because they did not know how to deal with a PDP. Some studies reported that the positive findings they found could be biased by having a self-selected group of PDP users who might already be enthusiastic and motivated (Bullock et al., 2007; Evans et al., 2002).

\section{Implementing PDPs}

The previous section made it clear that implementing a PDP is complex. Implementing a PDP introduces a new approach to organizing professional development in schools. Fullan (2001) and Maurer (2002) argued that implementing a new policy or approach does not automatically mean that teachers act in the same way as management intended. Although teachers and management share the same goal, improving quality of education, they can have different views on how this goal should be accomplished (Leggett \& Bunker, 2006). According to Kelchtermans et al. (2009), teachers have their own frame of reference that determines how they make sense of and act on changes in policy or development at work. Spillane et al. (2002) explained that sense-making is a comprehension process based on individual's prior knowledge, beliefs and experiences, the context in which the policy is implemented and the representation of the policy.

\section{Theoretical framework of the study}

Our study focused on how teachers made sense of the implementation of a PDP and an interview cycle. To investigate this issue, we focused on their beliefs about using a PDP and analysed how these beliefs relate to teachers' characteristics. This knowledge can provide input to improve the communication (Fishbein \& Cappella, 2006) about the PDP and the guidance for using a PDP by adjusting it to these beliefs.

In order to explore teachers' beliefs about a PDP, a model is needed that explains why people decide to perform particular behaviour. We used the theory of planned behaviour (TPB; Ajzen, 1991; Fishbein \& Ajzen, 2010) because it is a well-known model in the domain of health science to predict and understand people's intention to behave in a particular way. TPB is explained in the next section in which using a PDP is the researched behaviour. 


\section{TPB}

TPB (see Figure 1) assumes that people's decision to perform behaviour is reflected in their intention. The intention to perform the behaviour is influenced by three primary determinants or psychosocial variables, which are based on beliefs that people have about particular aspects of the behaviour (Kreijns et al., 2013; Fishbein \& Ajzen, 2010). These variables are attitude, subjective norm and perceived behavioural control (PBC). Attitude is the overall feeling of favourableness or unfavourableness towards using a PDP, for instance believing that completing a PDP is useful. Subjective norm concerns the perception of whether or not important others think one should or should not complete a PDP. For example, teachers perceive that their direct supervisor thinks that they should complete a PDP. PBC refers to the perceived ease or difficulty of using a PDP; that is, do teachers think that they are able to complete a PDP, taking into account the factors that might facilitate or inhibit this?

Each of these three variables, in turn, is based on the underlying beliefs that people have about using a PDP. Attitudes are based upon beliefs about consequences (i.e. they are outcome beliefs) of using a PDP and their evaluation. For example, completing a PDP will lead to more insight into teachers' learning needs. Normative beliefs determine the subjective norms people have, encompassing beliefs about whether or not important others (e.g. school staff, colleagues and students) think that one has to perform or not perform the target behaviour weighed against the individual's motivation to comply. Efficacy beliefs concern factors that are likely to facilitate or inhibit the behaviour, and how they can be overcome determines PBC. For example, filling in a PDP requires that teachers get the necessary tools and facilities, such as access to school policy plans to align personal development with school development.

TPB takes into account the uniqueness of particular behaviour and that different populations of teachers may have different outcome, normative and efficacy beliefs. For instance, senior teachers may have a negative attitude about the PDP as they have never used one during their long careers but are forced by their superiors to use one, whereas beginning teachers may be enthusiastic as they have already become acquainted with the PDP during their preparation and, thus, know its advantages (e.g. Mansvelder-Longayroux et al., 2007). Hence, to change behaviour, it is important to consider the particular population and the kinds of underlying beliefs that they have (Fishbein \& Cappella, 2006). For example, an intervention for senior teachers should orient towards an attitude change so that they no longer feel pressured by their superiors as the use of PDP becomes internalized.
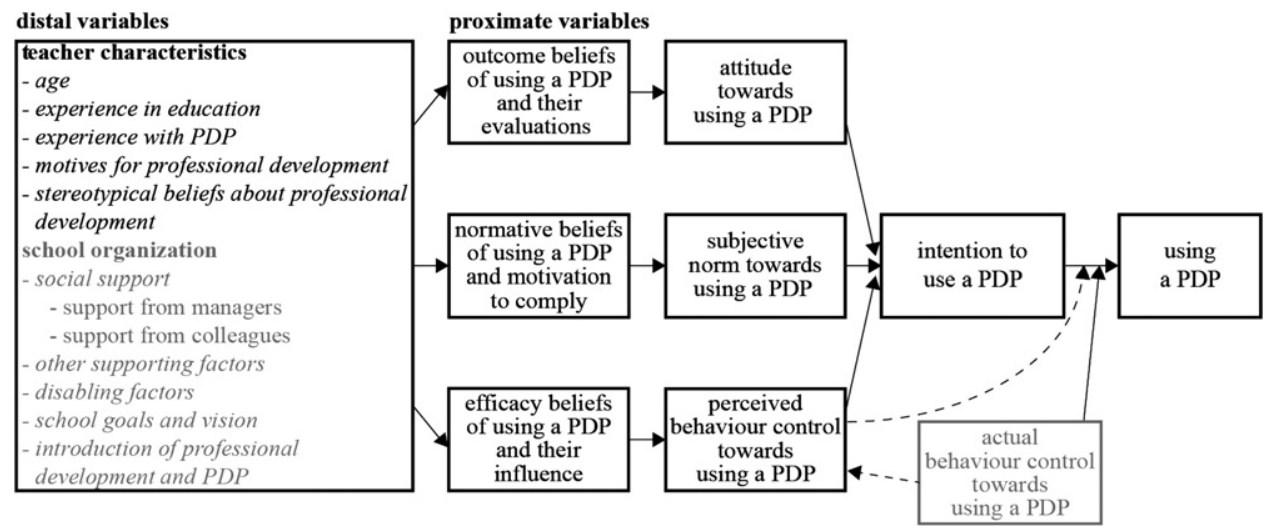

Figure 1: Theory of planned behaviour applied to using a professional development plan (PDP). School organizational factors and actual behaviour control were not included in this study. 
Figure 1 depicts a number of distal variables (i.e. background variables) that influence the intention via the proximal variables (i.e. the psychosocial variables). The distal variables encompass teacher characteristics and school organizational factors. In this research, we do not focus on school organizational variables, but on teacher characteristics and teachers' outcome, normative and efficacy beliefs.

\section{Teacher characteristics}

Teacher characteristics are age, years of experience in education, experience with a PDP, motivation for professional development and general beliefs about professional development. All these variables related to teacher characteristics (Smith \& Tillema, 2001; Van Eekelen et al., 2006) might affect the outcome, normative and efficacy beliefs, and through them the intention to use a PDP for professional development. For example, a teacher may think that things are working fine as they are and not see a need to professionalize. This teacher probably does not perceive the PDP as a valuable instrument.

\section{Methodology of the current study}

Whereas most research on TPB uses self-reporting questionnaires (such as Fishbein \& Cappella, 2006), we, in contrast, conducted interviews to increase insight into the beliefs that teachers have about using a PDP (Merriam, 2009). To uncover a range of possible beliefs (i.e. the outcome, normative and efficacy beliefs), we interviewed 41 teachers from five different schools. The interviews aimed to provide answers to the following questions:

1. What are the teachers' beliefs regarding using a PDP?

2. What teacher characteristics influence beliefs regarding using a PDP?

3. What groups (i.e. clusters) of teachers with similar beliefs and characteristics can be identified?

We applied qualitative and quantitative analyses to explore teachers' beliefs and characteristics (Miles \& Huberman, 1994; Namey et al., 2007) in order to identify different clusters of teachers to determine how specific interventions for these clusters can be designed.

\section{Context}

The Dutch government initiated the Education Professions Act, which prescribed that teachers in primary and secondary schools should file their development in a dossier (Ministry of Education, Culture \& Science, 2010). As a result, many Dutch schools invested in their human resource development policy by introducing a new job structure, implementing PDPs and other similar instruments.

For our study, two primary and three secondary schools dispersed over the Netherlands were approached as they had already implemented a PDP in their professional development cycle. The requirements of the government were similar for both school types. Teachers from these schools could express their beliefs based on the experiences that they had in completing a PDP. These experiences may go back from 1 to 5 years depending on when the school had implemented a PDP-based professional development cycle.

\section{Participants}

Forty-one teachers (12 primary school and 29 secondary school teachers) participated in the study. Sixteen of the participants were male and 25 female. The mean age of the participants was 39.1 [standard deviation $(\mathrm{SD})=11.1$ ] and the mean years of experience $13.7(\mathrm{SD}=10.2)$. 


\section{Instruments: the teacher interview}

The data collection was based on a semi-structured interview approach. The interviews were held from November 2010 until January 2011.

The first part focused on demographic data: age and years of experience in education. Teachers were also asked to describe the steps they had to take to complete a PDP.

The second part of the interview focused on teachers' beliefs about using a PDP. They were asked to explain their most important reason for using a PDP. The interview proceeded by examining the psychosocial variables and exploring the underlying outcome, normative and efficacy beliefs in line with TPB; that is, the questions referred to:

- attitude and outcome beliefs focusing on advantages and disadvantages;

- subjective norm and normative beliefs focusing on social pressure; and

- $\quad$ PBC and efficacy beliefs focusing on confidence in completing a PDP.

The third part of the interview explored the teacher characteristics: motives for professional development, general beliefs about professional development and prior experience with a PDP.

\section{Procedure}

The interview questions were practised with colleagues and one teacher. The interview protocol was adjusted based on their feedback.

To ensure having a range of different teachers regarding age and PDP-related beliefs, teachers were selected by the school principal as she or he knew the teachers personally. The interviews lasted between 20 and $60 \mathrm{~min}$. All the interviews were recorded, transcribed and analysed.

\section{Analysis}

We conducted qualitative and quantitative analyses. An exploratory analysis was first performed to elicit teachers' outcome, normative and efficacy beliefs, and the teachers' characteristics. To identify clusters of teachers with similar beliefs, a hierarchical cluster analysis was performed (Miles \& Huberman, 1994; Namey et al., 2007). Non-parametric tests were used to determine whether or not the teachers' characteristics differed between the clusters and were related to teachers' beliefs.

First, transcripts of the interviews were coded in NVivo version 9 (QSR International Pty Ltd, Doncaster, Victoria, Australia) by the researcher and a colleague who was ignorant of the research but received training on how to code the interview fragments; these interview fragments were extracted from the interview data by the researcher. The coding process was iterative, indicators and their interpretations were discussed, and ambiguous interview fragments were excluded from coding. This process was continued until a satisfactory intercoder reliability according to Landis and Koch (1977) was achieved; we achieved a Cohen's kappa of 0.71, which is 'substantial'.

The second step comprised identifying clusters of similar teachers. To that end, three main clusters were formed based upon what teachers had said about the most important reason they had to complete the PDP. These reasons were that (1) it was mandatory, (2) although it was mandatory, it also had clear advantages, and (3) it had clear advantages, and completing the PDP was not seen as an obligation at all. Subclusters were further identified using SPSS version 19 (QSR International Pty Ltd) hierarchical cluster analysis. Hierarchical cluster analysis is an explorative methodology that is used to find clusters of similar observations in a data set (Guest \& McLellan, 2003). Input for this analysis is a proximity matrix in which the rows and columns represent the teachers, and the content of the cells the 'distance' between the participants. The proximity matrix is calculated by SPSS (prior to the actual hierarchical cluster analyses) based on the responses of the participants regarding the three variables attitude, subjective norm and PBC. In particular, teachers' responses to attitude were divided into 
(1) negative, (2) neutral and (3) positive. Responses to subjective norm were divided into (1) high pressure, (2) low pressure and (3) no pressure. Reactions to PCB were summarized as (1) difficult, (2) neutral and (3) easy. The resulting clusters were presented in a conceptually ordered matrix (Miles \& Huberman, 1994) in which the responses of teachers on all variables were summarized per cluster and per variable (see Appendix).

The last step was to determine whether or not the teachers' individual characteristics had an influence on the beliefs that teachers had. The Kruskall-Wallis test was conducted to analyse whether or not the teachers' characteristics differed between the clusters and the psychosocial variables attitude, subjective norm and PBC. The Jonckheere-Terpstra test was used to determine whether or not these differences had a meaningful order: for example, senior teachers had a more negative attitude than younger teachers.

\section{Results}

The results are presented according to the three research questions. The first section explains results regarding teachers' beliefs about using a PDP. The second section describes the teacher characteristics that might influence teachers' beliefs. The last section presents the clusters of teachers. The Appendix can be consulted for a complete overview of teachers' responses on the different variables.

\section{Proximal variables}

Figure 2 provides a summary of how all participants responded to the questions related to the psychosocial variables. Participants differed on the most important reason for completing a PDP. Almost half of the interviewed participants indicated that they completed a PDP because it had advantages for them. Five participants felt pressured to complete one but mentioned that the PDP had advantages for them. Sixteen participants completed a PDP because it was mandatory.

\section{Attitude and outcome beliefs}

Twenty-four participants were positive about completing a PDP. Thirteen participants were neutral. They argued that it was useful to develop yourself but doubted the value of the PDP in this process. Four participants were negative: they thought it was superfluous and did not see advantages for themselves.

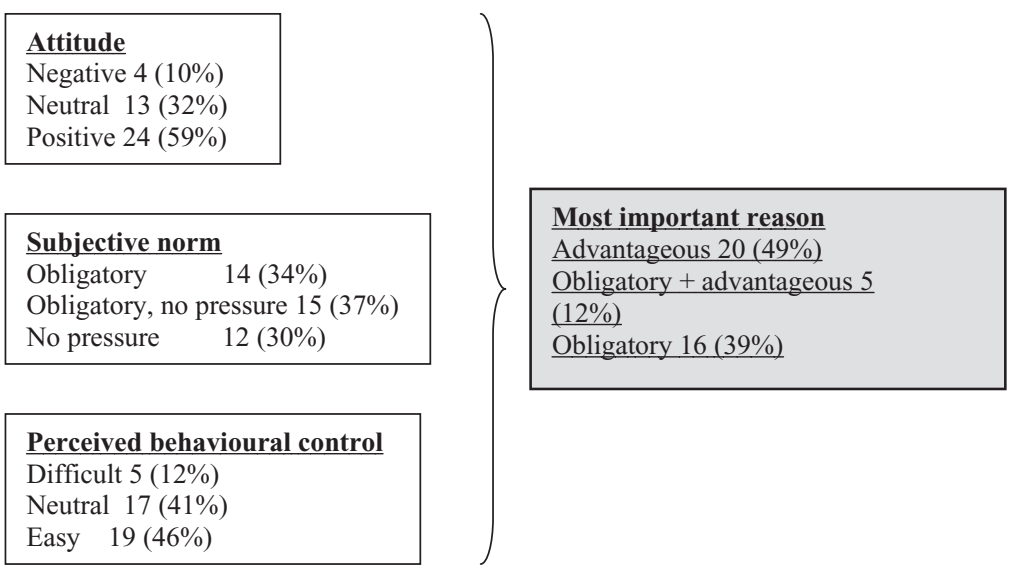

Figure 2: Overview of responses on most important reason, attitude, subjective norm and perceived behavioural control expressed with percentages of the total sample. 
All participants, except for one, mentioned advantages. Thirty-four participants considered the PDP as an instrument that supports their development. By filling in a PDP, they took time to reflect on their performance and formulate learning goals. Ten participants used the PDP for their career, to reflect on their ambitions or to attain a higher salary scale. Nine participants found it valuable for their supervisor, to discuss their development and make arrangements. The PDP also made it possible to make themselves visible in the organization, receive appreciation for performance and improve the quality of education.

Thirty-one participants mentioned disadvantages. The main disadvantage was the lack of time and the extra work it cost. Some participants experienced completing a PDP as a waste of time. Other disadvantages were comments on the format: for example, it was too rigid and leading. Some participants claimed that the PDP should include an assessment and more opportunities for growth in salary and responsibilities. Other participants thought that completing a PDP was not necessary because professional development was already occurring, it did not match their professional development or they thought that they were already performing well.

\section{Subjective norm and normative beliefs}

The teachers were asked whether or not they felt pressured to complete a PDP. Twentynine participants explicitly mentioned that it was mandatory. Yet 15 of them did not feel pressure in completing one. Twelve participants felt no pressure at all, and six of them completed a PDP for themselves.

Participants were asked for persons who would think that it was important to fill in a PDP. These persons were the educational inspector, the board and management of the school, the direct supervisor, colleagues, students and parents. The direct supervisor and management were mentioned most, whereas students and parents were mentioned less. Two participants thought that nobody cared whether or not they completed a PDP. Teachers had the following beliefs about why these persons would think that it was important: completing a PDP is good for the development and well-being of teachers, and it improves the quality of education. Moreover, they thought that it provided the direct supervisor with an opportunity to prepare the development interviews and that it led to a pleasant and learning team.

\section{$P B C$ and efficacy beliefs}

Most participants thought that completing a PDP was not too difficult. Nineteen participants said that it was easy, 17 participants were neutral and five participants found it difficult. Beliefs about what was difficult or easy differed. Some participants thought that it was difficult to formulate goals, whereas others thought that it was easy to formulate learning goals. The same applied to other parts of completing a PDP: formulating strengths and weaknesses, making plans of action and describing competences.

\section{Teacher characteristics}

To answer the second research question, we analysed whether or not age and years of work experience related to the clusters and/or psychosocial variables. As well as that, we analysed the motives that teachers had to develop themselves and their past experience by using a PDP.

Age and years of work experience differed significantly between the main clusters regarding the most important reason to complete a PDP, respectively $H(2)=7.21$, $p<0.05$ and $H(2)=7.33, p<0.05$. A significant trend showed that teachers who completed a PDP because of its advantages were younger and had less experience than the teachers who did so because it was mandatory, respectively $J=346, z=2.39$ and $J=330$, $z=-1.99$.

Years of work experience differed significantly regarding attitude, $H(2)=7.74$, $p<0.05$. Teachers who had less work experience were more positive than teachers with more experience, $J=135, z=-2.45$. 
Four categories of motives for professional development were found based on teachers' responses: no motives for development, career, profession and challenge. It was possible for the responses of one participant to be related to more than one category. For example, a participant could answer that he or she wanted to be challenged in his or her work (challenge) and provide good lessons (profession).

The results indicated that 30 participants were motivated to do their job well. They wanted to be up to date and provide good education for the students. Twenty-nine participants were motivated to challenge themselves and learn more. Eight participants had career motives including growth in salary and responsibilities. Five teachers had no motive to develop themselves. Their concern was to earn a salary or they had no ambitions.

Fifteen participants had no experience with using a PDP. Eight participants had experience with performance interviews. Twenty-three teachers had completed a PDP in a former job, for their study or as a supervisor.

\section{Clusters}

As mentioned before, we first divided the participants into three main clusters based on the most important reason for completing a PDP: advantages, obligation and advantages, and obligation. We then explored the main clusters with hierarchical cluster analysis. Although it was not possible for all clusters, because teachers' responses varied on all three psychosocial variables, we tried to form homogenous clusters; that is, we aimed for a balance between not having too many clusters and still having meaningful clusters with enough similarity between the participants (Norusis, 2011). Using this principle, seven subclusters were formed. Figures 3, 4 and 5 show the dendrograms resulting from a hierarchical cluster analysis using the variables attitude, subjective norm and PBC. The thick line in Figures 3, 4 and 5 indicates the point where the clusters were formed. The dendrogram has to be read from left to right. For example, Figure 3 shows that at the leftmost point, at zero, each participant corresponds exactly to one cluster. The rightmost point, at 25 , shows two clusters into which the participants can be divided. The thick line was drawn between 15 and 20, indicating that we found three interpretable clusters.

The main cluster 'advantages' (20 participants) was further divided into three subclusters. The main cluster 'obligation and advantages' (five participants) and the main cluster 'obligation' (16 participants) were each divided into two subclusters. Some clusters remained rather small. For example, the second main cluster included only five participants who filled in a PDP because it was mandatory and it had advantages for them. The clusters ranged on a continuum of clusters from teachers who completed a PDP because of the advantages, had a positive attitude and did not feel pressured, to clusters with teachers who felt pressured and had a neutral to negative attitude (see Appendix). The third variable, PBC, did not seem to have any influence on the clustering: most participants felt competent to complete a PDP. Participants who found it difficult were divided between the clusters. Years of work experience differed significantly between the clusters, $H(6)=14.64, p<0.05$, whereas age and motives for professional development did not differ between the clusters. We now discuss each cluster in more detail.

\section{Cluster one}

This cluster included 12 participants who were positive about completing a PDP and felt no pressure. Some participants said that they completed a PDP for themselves.

E_F, a 34-year-old female teacher, was one of the teachers of this cluster. She had a positive attitude because according to her, it was good to formulate learning goals for the future and have a discussion with the direct supervisor. She said:

As a teacher you are the king or queen and nobody watches you, nobody says I think you teach very well. You only get feedback from students or when a colleague watches your lessons because of intervision or he or she accidentally needs scissors or something like that. Conversations are about 
Dendrogram using average linkage (within groups) rescaled distance cluster combine

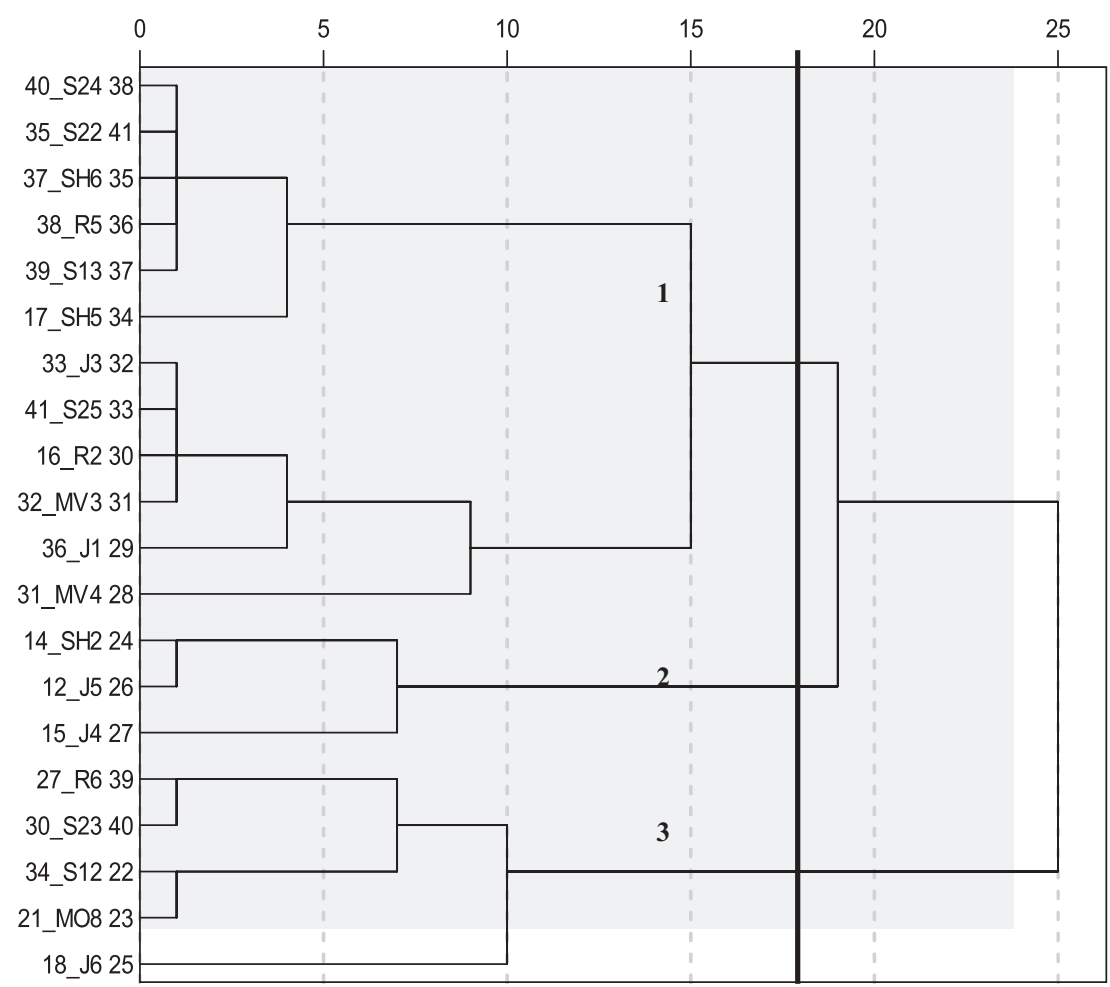

Figure 3: Dendrogram of hierarchical cluster analysis of 'advantages' with three subclusters. The vertical axis shows the participants.

the subject matter, not about how I function. I think it is very important to have such conversations from time to time.

The PDP was also useful for her to show her performance and how she developed herself to meet the necessary requirements for a higher position. She did not feel pressured because the PDP also benefited herself, the supervisor, management and colleagues. According to her, you had to take time to fill in the PDP. It is very important to look forward to what you want to achieve and learn.

\section{Cluster two}

Cluster two had five participants who completed a PDP because of its advantages. This cluster differed from cluster one regarding subjective norm. Although they completed a PDP mainly for its advantages, they admitted that it was mandatory. Three of them, however, said that they did not feel pressured.

One of these teachers was R_G, a 22-year-old female teacher. Although filling in a PDP was an obligation and she felt urged to make one, the PDP supported her professional development. She argued that it was important to keep on learning when finishing formal education: 'in order to differentiate, you have to be steady in front of the class. It is something you learn after initial education and that is what I want to learn now'. From her education, she was used to writing down the activities she did for work and to reflect on these activities. Using a PDP supported reflection on work and future goals. She was motivated to learn and to be challenged in her job 'to raise the standards for myself.' 
Dendrogram using average linkage (within groups) rescaled distance cluster combine

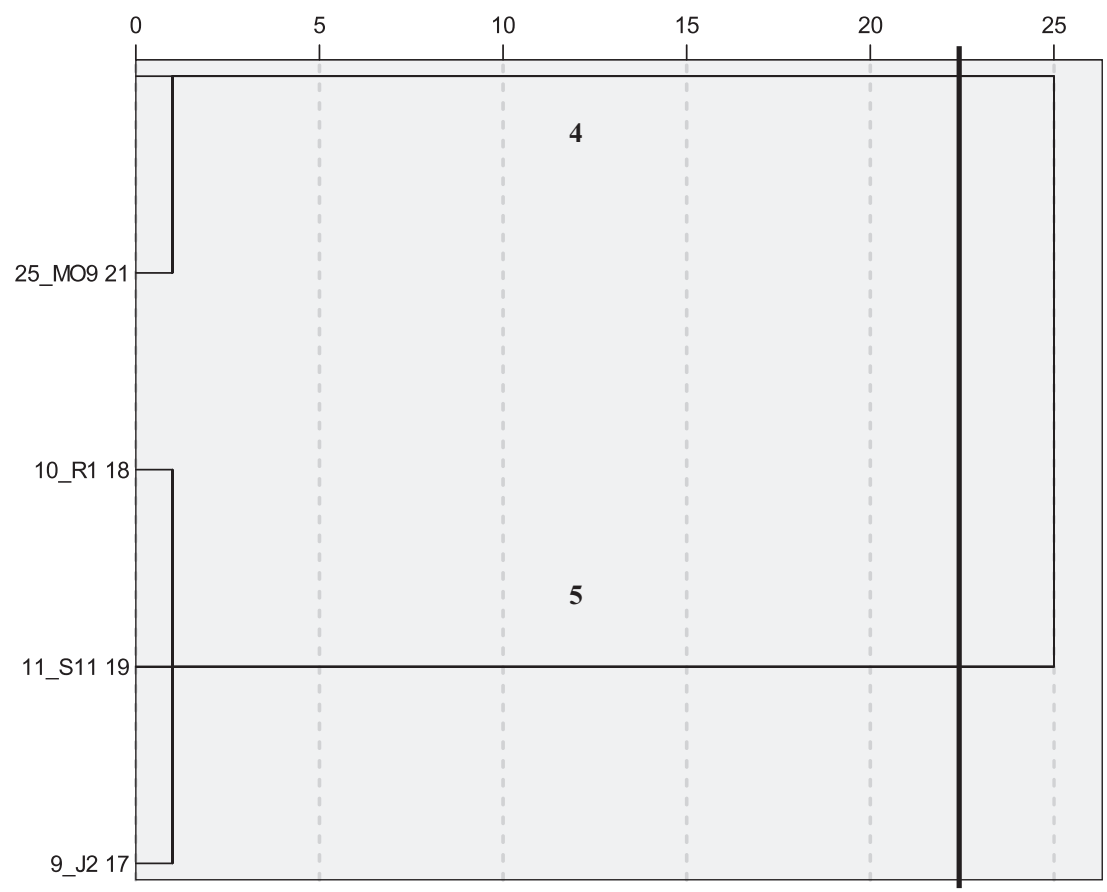

Figure 4: Dendrogram of hierarchical cluster analysis of 'obligation and advantages' with two subclusters. The vertical axis shows the participants.

\section{Cluster three}

The three participants within this cluster completed a PDP because it benefited them. Their attitude was, however, neutral. They emphasized that completing a PDP had advantages and disadvantages, and they were rather neutral about using a PDP. According to them, it focused too much on the future instead of on their current performance, and it took time. Completing a PDP was mandatory for them, but they felt no pressure.

L_B was a 26-year-old male teacher. The PDP provided him with an opportunity to discuss possibilities for development and to come to mutual agreements with the supervisor. The supervisor clarified his or her expectations of his performance, and he explained his demands and wishes regarding his career. However, he felt pressured by the organization to do extra things, for example, to follow courses:

I am happy that I graduated from school, that I can just work, earn money and have time to do other things. I am satisfied with the situation as it is . . actually the conversation made me feel pushed to do other things.

\section{Cluster four}

The two teachers in this cluster completed a PDP because it was required, but they also argued that it was important for their professional development.

B_A was a 35-year-old male teacher. Using a PDP supported him in becoming aware of his performance and being result oriented. However, the emphasis should be more on supporting personal development instead of professional development. According to him, a teacher can determine very well what is good for his or her profession, even if the school organization does not agree. He argued that the school should encourage teachers to use each others' expertise. His motive for professional development was the necessity to be up to date, especially regarding digital resources: 


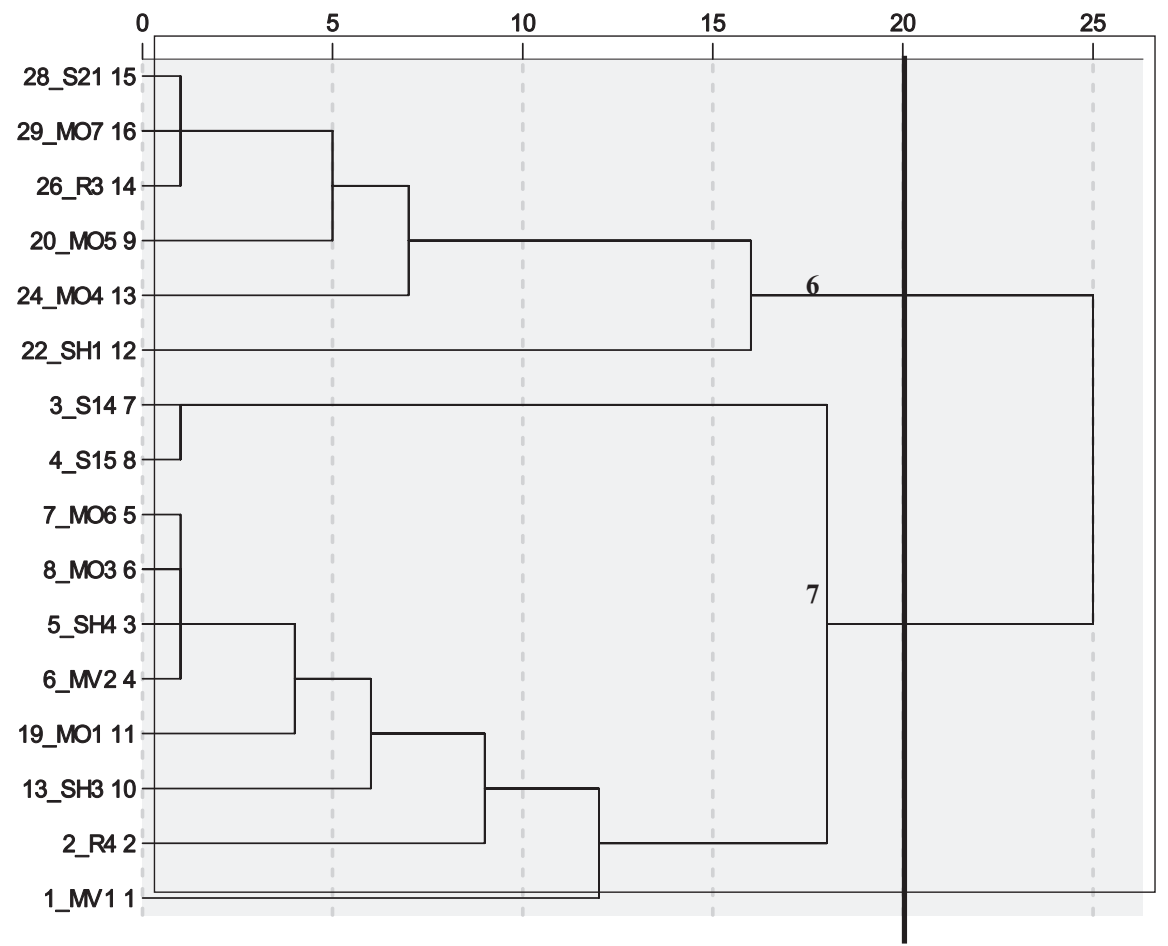

Figure 5: Dendrogram of hierarchical cluster analysis of 'obligation' with two subclusters. The vertical axis shows the participants.

I think that students can learn more individually than they do now; individual learning is possible with new digital tools. It is a big challenge to use these. If I do not follow these developments, I will miss the train in five years.

\section{Cluster five}

The three teachers in this cluster completed a PDP because it had advantages and it was mandatory. They had a neutral attitude. According to them, it was good to be aware of performance and to work on career. However, they doubted the value of the PDP for their professional development.

One of these participants was F_K, a 49-year-old male teacher. Using a PDP was mainly valuable for his career, to attain a higher salary scale. The PDP showed what he had accomplished. He found it meaningful to discuss strengths and weaknesses with his direct supervisor. However, writing things down could be interpreted in the wrong way and used against him:

I think it is important to have a relation of trust. This relation of trust can easily be affected . . a the moment that something is written down, and it is wrongly interpreted or used, there is not much you can do.

He believed that the management attached importance to PDPs because they wanted to know how teachers performed to determine whether or not a teacher was qualified for a higher function. The teacher himself was motivated to stay up to date, be challenged and have pleasure in his work, but he did not believe that the PDP supported him in his professional development.

\section{Cluster six}

The most important reason to complete a PDP for these six participants was the obligation. Despite the obligation, most of them felt no pressure, and they were positive 
about completing a PDP. Three participants believed that it was not very important for management that teachers completed a PDP.

One of the participants of this cluster was M_J, a 54-year-old female teacher. She perceived the PDP as an instrument to reflect, formulate goals, and make clear how the goals are attained. It should not, however, be too leading and become a dogma. As a former supervisor, she was familiar with supporting employees in their professional development and with the kind of questions that were posed in the PDP: 'if you have done this before, it becomes easier. At some point, you understand how you perform; you have received enough feedback from others about your strengths and weaknesses'. Regarding her professional development, she was mainly busy with doing research. That was something she really enjoyed, being curious and making progress by doing research.

\section{Cluster seven}

This cluster included ten participants who completed a PDP because it was mandatory, although four participants felt no pressure. Almost all the participants had a neutral to negative attitude. Some of the participants found that it was a waste of time and did not see the value for their professional development. They also had the impression that it had no priority for the management.

J_K was a 56-year-old male teacher. He perceived filling in a PDP as a waste of time. For him, the PDP was just a format:

Nowadays, things are all about the form, it is not about the content of something. You do it right when you just complete a PDP and make it look like a particular format. It is not necessary for me to complete a PDP. I think I am reasonably capable enough to reflect.

He thought that he could not write down what he wanted and chose to do that in another way. Despite these comments, he was motivated to do his job well and keep himself up to date to teach students well. When it is necessary to discuss something with his supervisor, this can be done without using a PDP and having a development interview.

\section{Discussion and conclusions}

In line with Spillane et al. (2002) and Kelchtermans et al. (2009), we believe that teachers' beliefs, their characteristics and the environment determine how they act on a policy or development. For example, a study of Beausaert et al. (2011a) revealed that if an employee perceives the PDP as a learning tool, it has a positive effect on undertaking learning activities and expertise growth. In two studies in the medical field (Bullock et al., 2007; Evans et al., 2002), the participants were positive about using a PDP, whereas in a study by Austin et al. (2005), pharmacists were less motivated and more frustrated about using a PDP as they found it time consuming and not valuable for their professional development. These studies suggested that the beliefs people had determined how they reacted to the implementation of a PDP. As these beliefs have not been systematically researched before, it is important to explore these beliefs to clarify what underlies teachers' decision to use a PDP.

This study aimed to explore teachers' beliefs about using a PDP and the characteristics that might influence these beliefs. The following section first discusses the first and second research question together by connecting the beliefs that teachers have about using a PDP to their characteristics. The headings of the subsections are based on typical statements that teachers made during the interviews. Subsequently, the clusters resulting from the teachers' beliefs are discussed. Based on these results, recommendations are formulated for adjusting interventions to particular beliefs and characteristics of groups of teachers.

\section{Teachers' beliefs related to their characteristics}

PDP as an instrument for development

Two other studies showed that when teachers perceive the PDP as a learning tool (Beausaert et al., 2011a), and when they are oriented towards learning and 
development, they are more positive about and successful in completing a PDP (Imhof \& Picard, 2009). This study confirmed the relations between the purpose of a PDP, motive for development and attitude regarding a PDP. Most teachers were positive about using a PDP and saw the tool as supportive of their development. Most teachers also wanted to develop themselves, provide good education and be challenged throughout their teaching career. Although the instrument was not used for assessment and promotion purposes, some teachers used a PDP to show their competences to apply for a high salary scale. Yet not every participant was convinced about the usefulness of the PDP, especially the more experienced teachers who had a more negative attitude. Some of them said that they were still meeting the standards. They were improving themselves anyway, and when it was necessary they contacted their supervisor immediately and did not wait for the development interview.

\section{PDP as another thing that we have to do}

Although most teachers were positive about using a PDP, most teachers regarded it as something extra. Also, some teachers, who found it important to think about their development, experienced it as extra work because of high workload. This is in line with other research that also indicated that some users found it a time-consuming task (Austin et al., 2005). Despite this obligation and extra work, many teachers felt no pressure to make one. This might indicate that when teachers get used to completing a PDP, it becomes part of their job, like marking exams.

\section{Completing a PDP is not too difficult}

Most teachers did not feel that it was difficult to complete a PDP. Difficulties that were mentioned included reflection on learning and formulation of learning goals. However, there were no quality standards for completing a PDP. Teachers could complete the form according to their own insights, which made it not too difficult.

\section{Clustering}

This study identified three main clusters and seven subclusters. Most differences appeared between subclusters one and seven (see Appendix). Cluster one included teachers who had a firm positive attitude towards the PDP. They were eager to learn and saw the PDP as advantageous for supporting their professional development, whereas teachers from cluster seven had a neutral to negative attitude and only completed a PDP because it was required. In between, clusters included participants who doubted the usefulness of a PDP. The main clusters differed in the teacher characteristic work experience. Teachers who completed a PDP because of its advantages had less work experience than teachers who filled in a PDP because it was obligatory. This might be due to the fact that teachers with less work experience finished their education recently, during which they probably used instruments for reflection and development (Mansvelder-Longayroux et al., 2007). This might have influenced their attitude positively and made them more aware of its advantages.

\section{Limitations}

Because our aim was to conduct an explorative study, we interviewed participants instead of using questionnaires. Because interviewing is a time-consuming research activity, a relatively small group of teachers was included. It was therefore not possible to generalize the results to a greater population. However, we involved a sample of teachers with different beliefs by interviewing teachers from different schools and of different age and experience. Because most teachers were assigned to participate in the research, teachers were selected who differed regarding these characteristics, and we did not have a bias of having only motivated teachers.

Because of the small sample and open-ended character of the interviews, it was not possible to measure correlations between different variables to determine which variables relate to each other. However, by using in-depth interviews, we gained more 
insight into the beliefs of teachers regarding the use of a PDP, which provides more direction for implementing a PDP successfully.

\section{Practical implications for interventions}

Based on the results, we propose some guidelines to adjust interventions to groups of teachers. In this study, it was clear for most teachers that the purpose was to promote professional development and not to formatively assess teachers for higher salary scales. This might have had a positive effect on teachers who feel more safe to reflect on themselves (Imhof \& Picard, 2009; Leggett \& Bunker, 2006). However, some teachers saw the advantage of using the PDP for their career and to attain a higher salary scale. It is therefore important to be clear about the ownership of the PDP and give teachers the opportunity to decide how they want to use it for their career.

In addition, attention should be paid to the meaning of a PDP for teachers' professional development. Some teachers, especially from clusters six and seven, said that the PDP did not match their professional development. They found the PDP an inflexible tool that did not address their everyday learning, or they did not see the necessity to formulate learning goals. It is therefore important to discuss the meaningfulness of a PDP and to make it clear that it is used to support self-regulated learning. To address teachers' comments on the PDP as a 'snapshot' and inflexible tool, the supervisor and teacher should take the initiative in discussing their development during the year.

Another recommendation is that management should show commitment to the use of PDPs. Some teachers, especially teachers who were neutral and negative, thought that the PDP did not have priority for management, and this might have influenced how they acted on using a PDP.

In line with other research (Leggett and Bunker, 2006), a common and important criticism by the teachers was the time it took to fill in a PDP, especially when they experienced high workload. Filling in a PDP costs time, especially when wanting to do it right, resulting in more understanding of one's own performance and meaningful learning goals. To relieve this feeling of extra workload, it is recommended to embed completing a PDP in the working practice, for example, by arranging sessions in which teachers get time and support to complete a PDP. When the PDP is not integrated in teachers' practice, it remains something extra to their work (Imhof \& Picard, 2009).

Teachers differed in the difficulties that they experienced with completing a PDP. Some teachers were eager to take up challenges and develop themselves; they knew what they wanted to achieve. In contrast, other teachers found it more difficult to formulate learning goals or did not have the ambition to develop themselves. It is important that teachers are supported (Beausaert et al., 2011a; Mansvelder-Longayroux et al., 2007). This support should not only aim to support critical reflection; this study made it clear that it is also necessary to pay attention to differences in beliefs and skills between teachers. The direct supervisor who is responsible for the development interviews should become aware of these differences and adjust their support to it. In particular, teachers who have more work experience, but have less experience with PDPs, should get more attention to become accustomed to reflecting and to directing their professional development.

\section{Future research}

In this study, we conducted a first exploration into identifying clusters of teachers with similar beliefs by seeking patterns in the conceptually ordered matrix of the participants' responses. We used hierarchical clustering as an objective and explorative methodology to identify clusters. Future research with a larger sample should examine the differences between the clusters in more detail, for example, by developing a questionnaire based on the TPB. Future research should also include schools in which it is not mandatory to complete a PDP. This research only includes schools where it was mandatory, which probably had a great influence on teachers' intention and decision to complete a PDP. When there is more variability in intention to complete a PDP, it is 
possible, especially when using questionnaires, to validate the TPB and measure relations between the dependent variable intention and the other variables.

\section{References}

Ajzen, I. (1991), 'The theory of planned behavior', Organizational Behavior and Human Decision Processes, 50, 179-211.

Austin, Z., Marini, A. and Desroches, B. (2005), 'Use of a learning portfolio for continuous professional development: a study of pharmacists in Ontario (Canada)', Pharmacy Education, 5, 3/4, 175-81.

Beausaert, S., Segers, M. and Gijselaers, W. (2011a), 'The use of personal development plans and the undertaking of learning activities, expertise-growth, flexibility and performance: the role of supporting assessment conditions', Human Resource Development International, 14, 5, 52743.

Beausaert, S., Segers, M. and Gijselaers, W. (2011b), 'The Personal Development Plan Practice Questionnaire: the development and validation of an instrument to assess the employee's perception of personal development plan practice', International Journal of Training and Development, 15, 4, 249-70.

Beausaert, S., Segers, M., van der Rijt, J. and Gijselaers, W. (2011c), 'The Use of Personal Development Plans in the Workplace: A Literature Review', in P. Bossche, W. Gijselaers and R. Milter (eds), Building Learning Experiences in a Changing World. Advances in Business Education and Training III (Dordrecht: Springer), pp. 235-65.

Bullock, A., Firmstone, V., Frame, J. and Bedward, J. (2007), 'Enhancing the benefit of continuing professional development: a randomized controlled study of personal development plans for dentists', Learning in Health and Social Care, 6, 1, 14-26.

Driessen, E., Van Tartwijk, J., Van der Vleuten, C. and Wass, V. (2007), 'Portfolios in medical education: why do they meet with mixed success? A systematic review', Medical Education, 41, $12,1224-33$.

Evans, A., Ali, S., Singleton, C., Nolan, P. and Bahrami, J. (2002), 'The effectiveness of personal educational plans in continuing professional development: an evaluation', Medical Teacher, 24, $1,79-84$.

Fenwick, T. (2003), 'Professional growth plans: possibilities and limitations of an organizationwide employee development strategy', Human Resource Development Quarterly, 14, 1, 59-77.

Fishbein, M. and Ajzen, I. (2010), Predicting and Changing Behavior: The Reasoned Action Approach (New York: Psychology Press).

Fishbein, M. and Cappella, J. N. (2006), 'The role of theory in developing effective health communications', Journal of Communication, 56, 1, 1-17.

Fullan, M. (2001), The New Meaning of Educational Change (New York: Teachers College Press).

Guest, G. and McLellan, E. (2003), 'Distinguishing the trees from the forest: applying cluster analysis to thematic qualitative data', Field Methods, 15, 2, 186-201.

Imhof, M. and Picard, C. (2009), 'Views on using portfolio in teacher education', Teaching and Teacher Education, 25, 149-54.

Kelchtermans, G., Ballet, K., Peeters, E. and Verckens, A. (2009), 'Goede praktijkvoorbeelden als hefboom voor professionalisering? Een explorerend onderzoek naar determinanten en kritische kenmerken', Pedagogische Studiën, 86, 161-84.

Kreijns, K., Vermeulen, M., Kirschner, P. A., Van Buuren, H. and Van den Acker, F. (2013), 'Adopting the integrative model of behavior prediction to explain teachers' willingness to integrate ICT in their pedagogical practices: a perspective for research on teachers' ICT usage in pedagogical practices', Technology, Pedagogy and Education, 22, 1, 55-71.

Landis, J. R. and Koch, G. G. (1977), 'The measurement of observer agreement for categorical data', Biometrics, 33, 1, 159-74.

Leggett, M. and Bunker, A. (2006), 'Teaching portfolios and university culture', Journal of Further and Higher Education, 30, 3, 269-82.

Mansvelder-Longayroux, D. D., Beijaard, B. and Verloop, N. (2007), 'The portfolio as a tool for stimulating reflection by student teachers', Teaching and Teacher Education, 23, 1, 4762.

Maurer, T. J. (2002), 'Employee learning and development orientation: toward an integrative model of involvement in continuous learning', Human Resource Development Review, 1, 1, 9-44.

Merriam, S. B. (2009), Qualitative Research and Case Study Applications in Education (San Francisco, CA: Jossey-Bass).

Miles, M. B. and Huberman, A. M. (1994), Qualitative Data Analysis (Thousand Oaks, CA: Sage Publications). 
Ministry of Education, Culture and Science (2010), Nota werken in het onderwijs 2011. Available at http://www.rijksoverheid.nl/documenten-en-publicaties/rapporten/2010/09/21/nota -werken-in-het-onderwijs-2011.html (accessed 3 April 2012).

Namey, E., Guest, G., Thairu, L. and Johnson, L. (2007), ‘Data Reduction Techniques for Large Qualitative Data Sets', in G. Guest and K. MacQueen (eds), Handbook for Team-Based Qualitative Research (Lanham, MD: Altamira Press), pp. 137-62.

Norusis, M. J. (2011), IBM statistics 19 advanced statistical procedures companion. Available at http:/ / www.norusis.com/pdf/SPC_v19.pdf. (accessed 3 April 2012).

Orland-Barak, L. (2005), 'Portfolios as evidence of reflective practice: what remains "untold" ', Educational Research, 47, 1, 25-44.

Smith, K. and Tillema, H. (2001), 'Long-term influences of portfolios on professional development', Scandinavian Journal of Educational Research, 45, 2, 183-203.

Smith, K. and Tillema, H. (2003), 'Clarifying different types of portfolio use', Assessment and Evaluation in Higher Education, 28, 6, 625-48.

Spillane, J. P., Reiser, B. J. and Reimer, T. (2002), 'Policy implementation and cognition: reframing and refocusing implementation research', Review of Educational Research, 72, 3, 387-431.

Tigelaar, D. E. H., Dolmans, D. H. J. M., De Grave, W. S., Wolfhagen, I. H. A. P. and van der Vleuten, C. P. M. (2006a), 'Participants' opinion on the usefulness of a teaching portfolio', Medical Education, 40, 4, 371-8.

Tigelaar, D. E. H., Dolmans, D. H. J. M., De Grave, W. S., Wolfhagen, I. H. A. P. and van der Vleuten, C. P. M. (2006b), 'Portfolio as a tool to stimulate teachers' reflections', Medical Teacher, 28, 3, 277-82.

Van Eekelen, I. M., Boshuizen, H. P. A. and Vermunt, J. D. (2006), 'Self-regulation in higher education teacher learning', Higher Education, 50, 447-71.

Wade, R. C. and Yarbrough, D. B. (1996), 'Portfolios: a tool for reflective thinking in teacher education?', Teaching and Teacher Education, 12, 1, 63-79.

Wolf, K. and Dietz, M. (1998), 'Teaching portfolios: purposes and possibilities', Teacher Education Quarterly, 25, 9-22.

Zeichner, K. and Wray, S. (2001), 'The teaching portfolio in US teacher education programs: what we know and what we need to know', Teaching and Teacher Education, 17, 5, 613-21. 


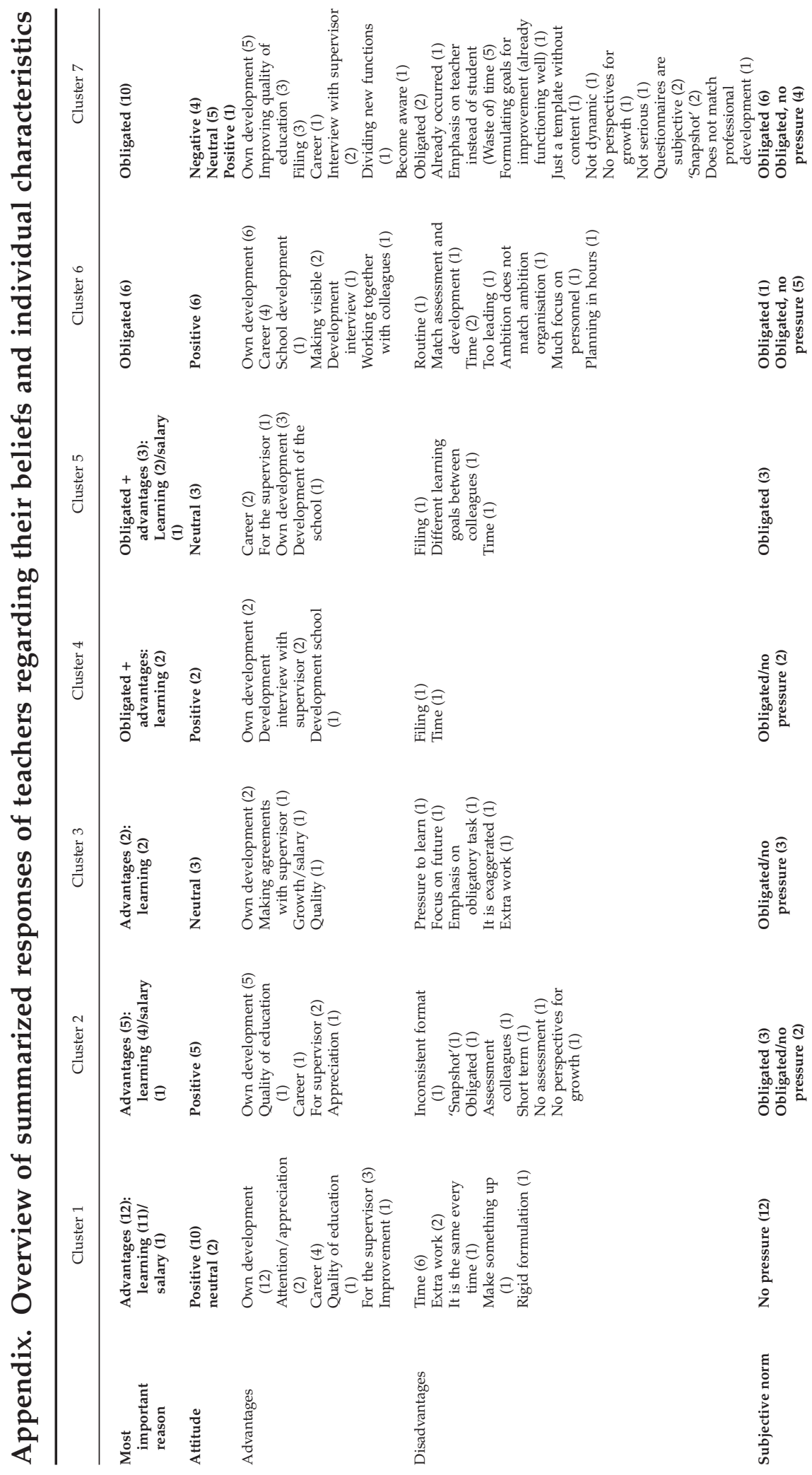

Teachers' beliefs about PDPs 277 (c) 2013 John Wiley \& Sons Ltd. 


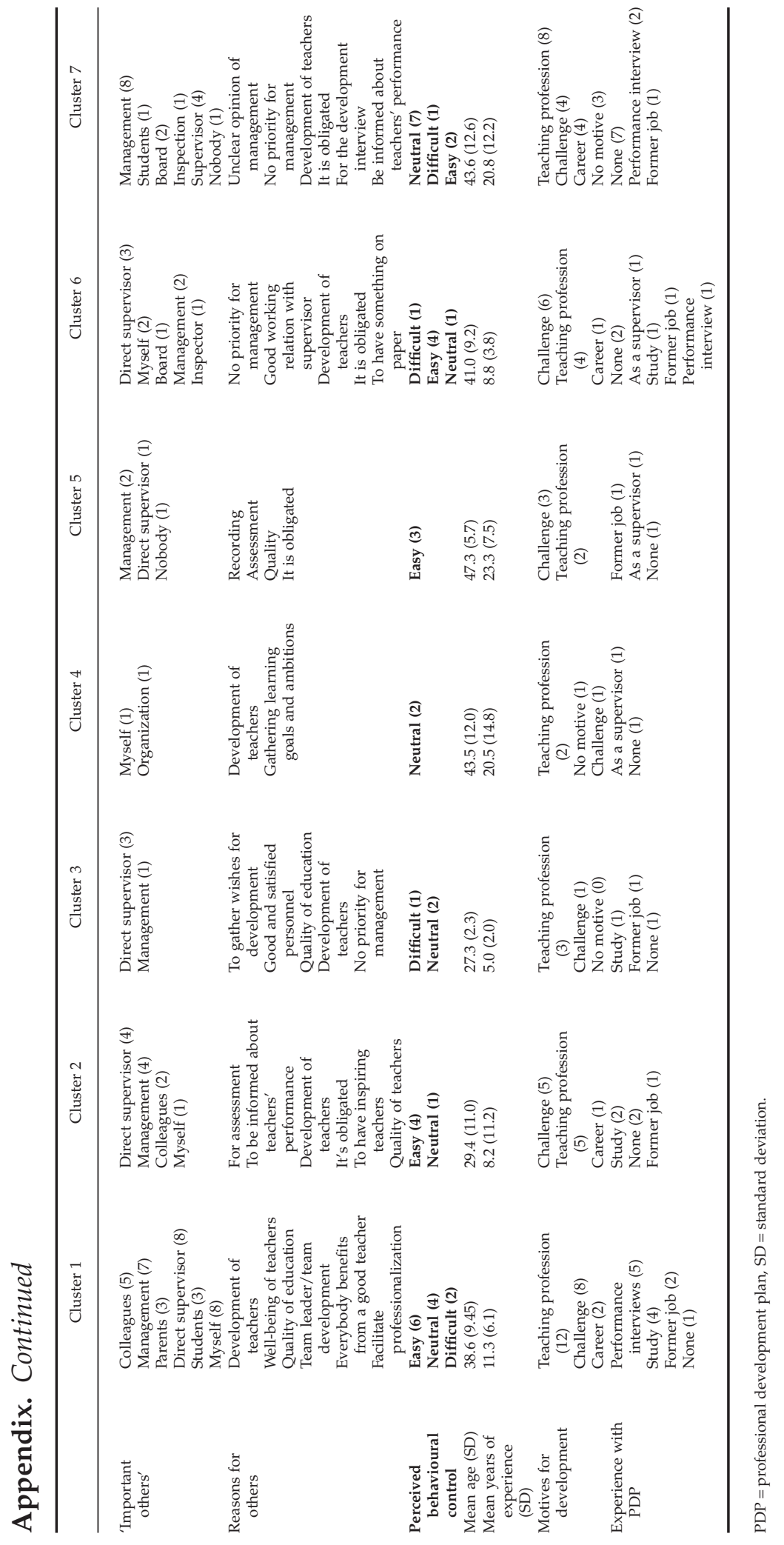

278 International Journal of Training and Development

() 2013 John Wiley \& Sons Ltd. 